\title{
Restoration of the Great Telescope at Birr Castle Demesne, Ireland
}

\author{
Ireland's Historic Science Centre
}

By courtesy of The Birr Scientific and Heritage Foundation
1840-1900

Astronomy and Engineering

In the mid 19th. century, some quite extraordinary feats of science and engineering were accomplished by the Parsons family in their home at Birr Castle in Birr, Co Offaly (then King's County). William Parsons, Third Earl of Rosse, began building telescopes and an observatory while still in his twenties.

In 1840, unhappy with the amount of light he could gather in his $3 \mathrm{ft}$. telescope, he determined to build an enormous $6 \mathrm{ft}$. diameter telescope. Located in the middle of the castle park, he designed and constructed it himself, using local craftsmanship: estate workers which the Earl trained himself as coopers, carpenters, blacksmiths, and metal workers, with no more than the means then available in central Ireland. The telescope mirror was a feat of engineering in itself. The huge $6 \mathrm{ft}$. speculum (mirror: speculum metal is a mixture of copper and tin) was paraboloid in shape and weighed some three tonnes. It was cast in a furnace constructed at the bottom of the moat and fired by turf off the local bogs. The alloy was cooled to ambient temperature in an annealing oven. Great care had to be taken with the proportions of copper and tin used, and with the annealing process, to prevent the mirror from cracking during cooling. Three months' cooling and then polishing it to the standard required, without blemish, was an art, a work of true genius.

The telescope tube was $56 \mathrm{ft}$. long and was suspended between two $60 \mathrm{ft}$. high limestone walls. It was a reflecting telescope, where the principle mirror is in the base of the tube and the observer looks through an eyepiece close to the mouth. The light from the stellar object is reflected from the base mirror to a secondary mirror in the centre of the tube, set at an angle of $45^{\circ}$, opposite the eyepiece. As the tube was raised to the skies, the observer had to maintain his position at the top of the tube. Ladders enabled him to reach viewing platforms and stand on a series of galleries which could be raised and lowered as desired, suspended from the surrounding walls using a conglomerate of pulleys, chains, weights and windlasses.

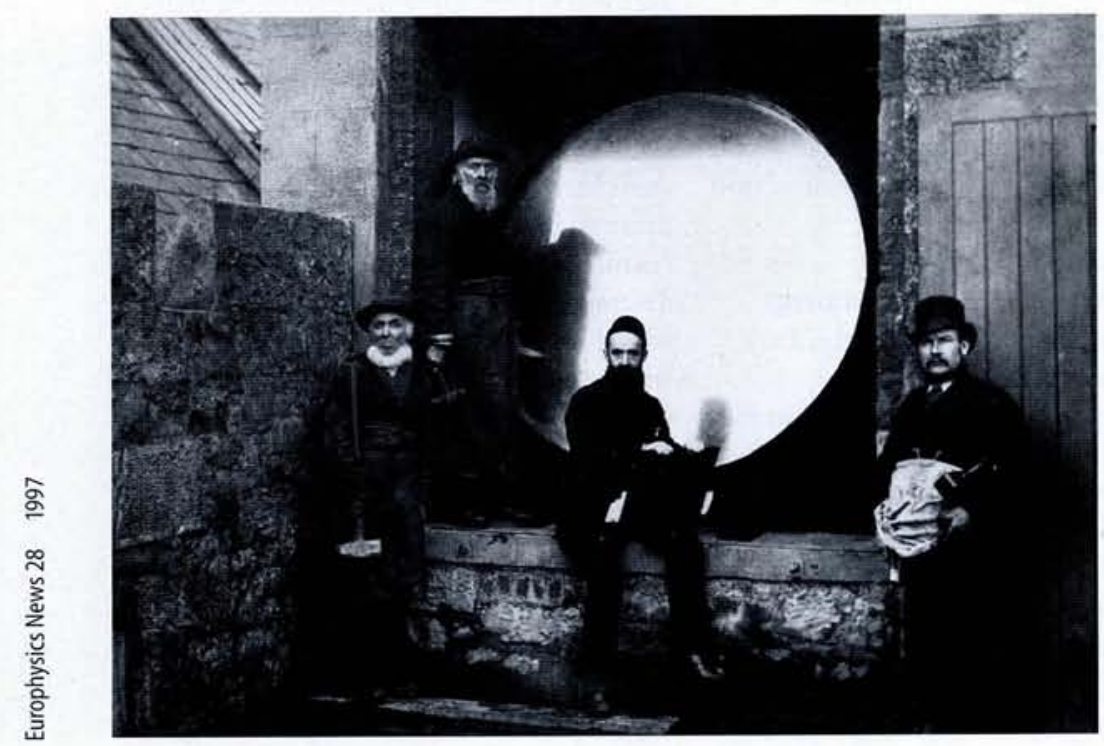

After completion, the instrument was tested by the Earl and a number of astronomers who came to work with him at Birr. The immense power of the telecope (it remained the largest in the world until 1917) enabled the Earl to see further into space than anyone had before him, and attracted astronomers from as far afield as the US, Australia and Imperial Russia, whence they made the pilgrimage to Birr as the only observatory in the world which could see so far out into space.

The third Earl became especially interested in the nebulae and particularly in those of a spiral nature. It was in the spring of 1845 that he made his first major discovery: that some galaxies had a spiral shape, rather than being just pinpricks of light. He recorded them in drawings the clarity of which was not matched until the powerful photography of the next century. And in the same year 1845 the Earl identified and named the Whirlpool nebula, M51. The beautiful structure of these objects has fascinated atronomers ever since. The observation of the spiral nebula was the climax of the early use of the Great Telescope. For this achievement, and other discoveries, the third Earl of Rosse was made President of the Royal Society in which capacity he oversaw the Great Exhibition in London in 1851, and that of Dublin in 1853.

For the next 50 years astronomers continued to work at Birr. The fourth Earl was equally interested in astronomy and built another telescope, albeit miniature in comparison, to measure the heat of the moon. The last observations through the Great Telescope took place in the early 1900's and finally, after the fourth Earl's death in 1908, the telescopes were abandoned and dismantled in 1914 .

Except for one: the Great Telescope defied dismantling; it remained on the front lawn, like a gothic folly covered in trees, shrubs and bushes, awaiting its resurrection.

\section{3-1998 \\ Restoration}

In 1993, the current Earl of Rosse set in motion a project to restore the telescope, and in 1995 funding was secured from the government and the European Regional Development Fund to start the restoration. Private donations are being solicited from individuals and companies to make up the balance of the funds required. Subcontractors were sought: stonemasons to work on the supporting 


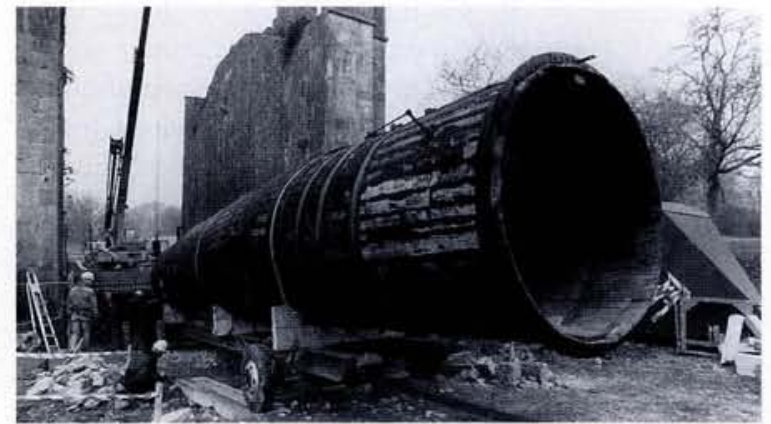

Removing the Tube

walls, specialist metalworkers to recreate the viewing platforms and galleries, specialist joiners to develop a new wooden tube (the greater part of the original having succumbed to rot) and electricians to make the mechanisms work electronically. So, as well as being raised manually, the computerised telescope will now work at the press of a button.

In the Spring of 1994 engineering consultants were appointed and began to assess the feasibility of the telescope's restoration. No original drawings existed. To assess the weight, rediscover the working mechanisms, redesign the viewing platforms and finally make new drawings it was necessary to explore the pits, study old photographs, delve into archives and make exploratory digs to see what might have remained of the original structure.

A great discovery in the archive was the diary of an astronomer who had spent six months at Birr in 1848. In it is a detailed description of how the mirror was ground, polished and tested over a period of three months. A further find was a drawing of the telescope by the naturalist Mary Ward, a cousin of the third Earl. She drew in meticulous detail and described very specifically how the telescope worked.

Tenders were received and final contracts awarded at the end of 1995, and the main contractor came on-site in February 1996. In March the tube was separated from the speculum box and removed amid great anxiety. It had been resting on the ground for almost 100 years: despite the care and preparatory work, might it collapse when removed from its mountings?

Gently, slowly the great tube was lifted and shifted onto a low loader without mishap and pulled away to the workshop for re-building. It was a mammoth task: the wooden tube was taken apart, a light steel framework was built and the rotted planks replaced. Iron bands were cleaned and painted, brackets and bolts were renewed.
Meanwhile the stonemasons had commenced work: the west and east walls were fully restored. In May 1996, the heavy metal plates to secure the galleries were positioned in the west wall. The galleries were reconstructed, a period windlass was located (on the Dublin docks!) and all the other mechanical parts fabricated.

One of the most important tasks was testing the universal joint, the massive cast iron joint about which the telescope rotated. It had been cast by the third Earl in 1844 and had survived the dismantling of the telescope at the beginning of the century. Would it still be in good enough condition to take the strain, some 150 years later, of the combined 12 ton weight of the newly built tube with its mirror and all the weights and chains? A crane and 15 tons of concrete weights were brought to the site, on a bitterly cold and wet 1 st. May. Simultaneously, carefully calculated horizontal loads were applied by jacks thrust off the adjoining walls, to simulate the actual loads which would be applied by the telescope in action; a total of six tests were applied. Would the old cast iron joint hold? As each combination of loads was added, tests were conducted to establish if there was any sign of movement or distress in the joint or the masonry foundation underneath. Eight hours later the final, most critical test was applied - a nerve wracking moment! But it worked; the old joint can be put back into action.

In early September, the restored tube was driven slowly from the workshop back to Birr; like some great beast it prowled through the villages along the way. Back at the site, the mechanisms were being put into place in readiness for the reassembling: crane wheels, chains, turn-table and access ladders were installed and tested for safety. The lair was ready!

\section{Establishing the Meridian}

On 16th. June 1996 a team from the Irish Astronomical Association came to Birr to establish a true North-South alignment line - the "Meridian" - in order to set the Meridian Arc to be reconstructed on the inside face of the east wall. The team used the solar transit method to obtain the exact meridian. In a milestone ceremony, on 18th. June Sir Bernard Lovell (Founder/Director, Jodrell Bank Radio Astronomy Laboratories) and Dr. A.J.F. O'Reilly (Chairman of the Council of Ireland's Historic Science Centre) reinstated the meridian stones at Birr. Three aligned stones were installed by the third Earl of Rosse in the early 1840's to ensure that the telescope was directly on the meridian line. One of the stones, due south, was still in situ but over the years, the other two had disappeared.

\section{The New Mirror}

Where to find a new mirror appropriate to a 19th. century telescope? The successful manufacture of the $6 \mathrm{ft}$. diameter mirror was undoubtedly the Third Earl's most important acievement. The surviving original mirror had been given to the Science Museum in London, when the telescope was dismantled in 1914. It is hoped that one day this mirror will be returned to Birr on loan as the central exhibit in the new Science Galleries also to be built there.

Meanwhile, the Great Telescope must work, and the many friends of the project have been searching for a company which could make a suitable replacement mirror. Among them Sir Bernard Lovell who searched the world, from America to Russia. It has been decided to make a metal mirror as before, but from aluminium. Negotiations have been successful with the physicists in University College London regarding the making of the new mirror and all the other optical and mechanical parts. It will take 18 months to produce. The commissioning of this element is outside the present budget and will require a separate fund-raising drive. However, it is hoped to install the new mirror by Spring 1999, when the Great Telescope at Birr will once again become fully operational.

The Great Telescope at Birr was opened for public viewing in February 1997 , from 9.00 am to $6.00 \mathrm{pm}$ daily. For further information contact: Brigid Roden Birr Castle Demesne Co Offaly

Tel: (0509) 20336 